\title{
Serum microRNA 106 and microRNA 223 as novel biomarkers in inflammatory bowel disease
}

\author{
Alaaudin Habib ${ }^{1 *}$, Ayman Minisi ${ }^{1}$, Mahmoud Awad ${ }^{1}$, Abdallah Essa $^{2}$, \\ Amany Khalifa ${ }^{3}$, Somaia Shehab-Eldeen ${ }^{2}$ \\ ${ }^{1}$ Internal Medicine, Faculty of Medicine, Mansura Univ., Egypt., ${ }^{2}$ Tropical Medicine, Faculty of Medicine, \\ Menoufia Univ., Egypt,. ${ }^{3}$ Clinical Pathology, Faculty of Medicine, Menoufia Univ., Egypt. \\ *alaahabib75@hotmail.com
}

Received: $14-5-2020$

Accepted: $22-10-2020$

\begin{abstract}
:
Background: Inflammatory bowel disease (IBD) involves mainly Crohn's disease (CD) and ulcerative colitis (UC). Distinguishing between the two diseases may be problematic in $15 \%$ of patients due to inconclusive findings on histopathology or endoscopy. miRNAs are non-coding RNAs composed of 18-23 nucleotides and are widely detected in the cells involved in variable pathological and physiological processes. The aim of this study is to assess if serum microRNA 106 and microRNA 223 (miR-223) can be reliable biomarkers in IBD patients. Methods: Serum levels of microRNA 106 and microRNA 223 (miR-223) were determined in 80 IBD patients by using the Transcript or First Stand cDNA, expression levels of serum miRNA in IBD patients and the control group and between active and inactive diseases were detected. Results: There was a significant increase in expression levels of serum miRNA 106 and miRNA 223 in IBD patients (UC and $\mathrm{CD}$ ) compared to the control group $(\mathrm{P}<0.001$, both). Also, There was a significant increase of expression levels of serum miRNA 106 and serum miRNA 223 with increased disease activity of IBD ( $\mathrm{P}<0.05$, both). Conclusions: The levels of miRNA 106 and miRNA 223 are higher in the peripheral blood of IBD patients and the elevation is more significant in the active disease. The miRNA 106 and miRNA 223 may be used as a novel biomarker in the diagnosis of IBD and evaluating the disease activity.
\end{abstract}

Keywords: miRNA, inflammatory bowel disease, Crohn's disease and ulcerative colitis.

\section{Introduction}

Inflammatory bowel disease including mainly Crohn's disease and ulcerative colitis. IBD usually develop due to complex interaction between immunologic, genetic, and environmental factors leads to significant changes in gene expression ${ }^{1-3}$.UC involves the colonic mucosa, causing continuous intense inflammation, however, the CD might involve the whole gastrointestinal tract; via immune reactive response mainly in the terminal ileum ${ }^{\mathbf{4} 5}$. The diagnosis of IBD is relying on clinical, laboratory, radiologic and endoscopic findings. Usually, the diagnosis of CD or UC is clear. However, if the dis- ease is only colonic, distinguishing between the 2 diseases will be inconclusive in up to $15 \%$ of cases due to indecisive findings on histopathology or endoscopy ${ }^{6-8}$. Due to the propensity for intermittent exacerbations and relapses efficient and frequent evaluation are essential for IBD patients ${ }^{9}$. Endoscopy has a crucial role in assessing mucosal lesions. However, this maneuver is usually costly and has some complications ${ }^{\mathbf{1 0}}$. Up till now, no ideal biomarkers to diagnose and monitor IBD. Erythrocyte sedimentation rate (ESR) and C-reactive protein (CRP) are mainly used in follow-up. However, mostly they are nonspecific, as their values increase in different inflammatory disorders or remain at normal values in active IBD patients ${ }^{\mathbf{1 1}}$. Fecal calprotectin is considered as a non-invasive biomarker for evaluating disease relapse among IBD patients. However, it is still nonspecific and is positive in other intestinal inflammatory disorders, as celiac disease, infectious enteritis ${ }^{\mathbf{1 2 , 1 3}}$. So, there is increasing demand in biomarkers with more specific diagnostic criteria for IBD and could distinguish between different phenotypes ${ }^{14}$. Micro RNAs are non-coding RNAs composed of 18-23 nucleotides and are extensively present in the cells involved in variable physiological and pathological $\operatorname{processes}^{15}$. MicroRNAs are involved in the regulation of different biologic processes, such as intestinal barrier function, endoplasmic reticulum stress, immune regulation, and gut microbiota interactions, to generate chronic mucosal inflammation ${ }^{16}$, 17. microRNAs may be involved in regulation of specific genes. It is well known that micro RNAs have important roles in the cell differentiation and organogenesis. Disturbances in expression of micro RNAs may lead to disease development ${ }^{18}$. micro RNAs have been found in the peripheral blood of some immunologic disorders such as rheumatoid arthritis and systemic lupuserythematosus ${ }^{19}$. Recent data detected abnormal expression of micro RNA profiles in the tissues and peripheral blood of IBD patients compared with healthy controls ${ }^{20,21}$. However, the data are conflicting in some studies as regards the relationships between micro RNA levels and disease activity $^{22}$. The aim of this study is to assess 
if serum microRNA 106 and microRNA 223 can be reliable novel biomarkers in IBD patients and their relation to disease activity.

\section{Patients and Methods}

Our study involved 80 IBD patients (40 patients with ulcerative colitis and 40 patients with Chron's disease) and 40 sex and age matched healthy individuals as a control group recruited from Riyadh Care Hospital (Outpatient and inpatient) from February to December, 2018. The diagnosis of IBD was based on the clinical, laboratory, radiological, endoscopic and histological investigations. All involved subjects signed informed consents. The research was consistent with The Declaration of Helsinki for human research ethics. The age of our subjects ranged between 18 and 68 years old. Montreal classification was used to define the site of the disease ${ }^{23}$. Clinical disease activity was measured by the Crohn's Disease Activity Index (CDAI) for $\mathrm{CD}$ and the Mayo clinical score for $\mathrm{UC}^{24,25}$. Clinical activity was defined as CDAI $\geq 150$ for active CD or Mayo clinical score $>2$ for active UC. Crohn's Disease Endoscopic Index of Severity (CDEIS) scores for CD and UCEIS scores for UC were determined after performing colonoscopy to assess the endoscopic activity ${ }^{26,27}$. CDEIS $>3$ for CD and UCEIS $>1$ for UC are the cut off values of disease activity in both diseases ${ }^{28,29}$. Infectious and malignant etiologies of colitis were excluded. Thorough history taking, including current and past medications and careful examination including, BMI were done. Serum samples for CBC, quantitative CRP \&ESR were collected.

Isolation of microRNA from the periheral blood The mirVana miRNA Isolation Kit (Ambion, Austin, TX) was used to isolate the total RNA according to instructions of manufacturer. The reverse transcription (RT) of miR-106 and 223 was manufactured through a reaction with the RT master mix by using the Transcript or First Stand cDNA Synthesis Kit(Roche, Germany, Penzberg).

\section{Statistical analysis}

All data were presented as the mean \pm SD. The Kruskal-Wallis test, followed by the "kruskalmc" function ("pgirmess" package), was the standard for intergroup comparisons. $\mathrm{P}<0.05$ was statistically significant. The Kruskal-Wallis test and Pearson correlation coefficient(r) analysis were applied via SPSS 13.0 software (SPSS, Inc., USA).

\section{Results}

Table (1) shows the demographic data of our studied patients. Table (2) shows a significant increase of expression levels of serum miRNA 106 in IBD patients compared to the control group, ( $\mathrm{P}$ $<0.001)$.

Table 1. The demographic data of our studied groups

\begin{tabular}{|c|c|c|c|}
\hline & Ulcerative Colitis & Crohn's disease & Control group \\
\hline Number & 40 & 40 & 40 \\
\hline Gender(male/female) & $24 / 16$ & $19 / 21$ & $23 / 17$ \\
\hline Age $($ mean \pm SD $)$ years & $40.7 \pm 12.8$ & $36.2 \pm 10.6$ & $42 \pm 7.8$ \\
\hline Duration of the disease (mean \pm SD)years & $10 \cdot 5 \pm 8 \cdot 5$ & $13 \cdot 7 \pm 5 \cdot 8$ & NA \\
\hline \multicolumn{4}{|l|}{ Exent of UC } \\
\hline E1: procistgmoiditis & 16 & - & - \\
\hline E2: left-sided & 14 & - & - \\
\hline E3: pancolitis & 20 & - & - \\
\hline \multicolumn{4}{|l|}{ Site of CD } \\
\hline L1: ileal & - & 8 & - \\
\hline L2: colonic & - & 16 & - \\
\hline L3: ileocolonic & - & 18 & - \\
\hline L4: upper disease & - & 0 & - \\
\hline \multicolumn{4}{|l|}{ Medications (n) } \\
\hline 5 - ASA & 21 & 8 & - \\
\hline Antibiotics & 0 & 5 & - \\
\hline Steroids & 18 & 15 & - \\
\hline Azathioprine & 4 & 5 & - \\
\hline 6-Mercaptopurine & 5 & 4 & - \\
\hline Methotrexate & 6 & 6 & - \\
\hline Biologics & 8 & 12 & - \\
\hline \multicolumn{4}{|l|}{ Disease behavior } \\
\hline - Active n (\%) & $27(67.5 \%)$ & $23(57.5 \%)$ & - \\
\hline - Quiescent n (\%) & $13(32.5 \%)$ & $17(42.5 \%)$ & - \\
\hline
\end{tabular}


Table 2. Comparison of expression levels of serum miRNA 106 in IBD patients and the control group

\begin{tabular}{ccccc}
\hline Parameter & $\begin{array}{c}\text { Ulcerative colitis } \\
\text { group }(\mathbf{n = 4 0})\end{array}$ & $\begin{array}{c}\text { Crohn's disease } \\
\text { group }(\mathbf{n = 4 0})\end{array}$ & $\begin{array}{c}\text { Control group } \\
(\mathbf{n}=\mathbf{4 0})\end{array}$ & P value \\
\hline $\begin{array}{c}\text { Fold change of serum } \\
\text { miRNA 106 (Mean } \pm \text { SD) }\end{array}$ & $2.38 \pm 1.13$ & $4.66 \pm 1.92$ & 1 & P 1 $<0.001$ \\
& & & & $\mathbf{P 2}<0.001$ \\
\hline
\end{tabular}

$\boldsymbol{P} \mathbf{1}=U C$ versus control, $\boldsymbol{P} 2=C D$ versus control, $\boldsymbol{P} 3=U C$ versus $C D$.

Moreover, a significant increase in serum miRNA 106 was found in CD versus UC. Table (3) shows a significant increase of expression levels of serum miRNA 223 in IBD patients compared to the control group, ( $\mathrm{P}<0.001)$. In addition, a significant inc-rease in serum miRNA 223 was found in CD versus UC. Table (4) shows the sensitivity and specificity of serum miRNA $106 \&$ serum miRNA 223 in patients of UC and CD. Table (5) shows a significant increase of the expression levels of serum miRNA 106 and serum miRNA 223 with increased activity of IBD (UC and $\mathrm{CD}),(\mathrm{P}<0.05)$.

Table 3. Comparison of expression levels of serum miRNA 223 in IBD patients and in the control group

\begin{tabular}{ccccc}
\hline Parameter & $\begin{array}{c}\text { Ulcerative colitis } \\
\text { group }(\mathbf{n = 4 0})\end{array}$ & $\begin{array}{c}\text { Crohn's disease } \\
\text { group }(\mathbf{n = 4 0})\end{array}$ & $\begin{array}{c}\text { Control group } \\
(\mathbf{n}=\mathbf{4 0})\end{array}$ & P value \\
\hline $\begin{array}{c}\text { Fold change of serum } \\
\text { miRNA 223 } \text { (Mean } \pm \text { SD) }\end{array}$ & $1.78 \pm 1.16$ & $3.18 \pm 1.18$ & 1 & P 1 $<0.001$ \\
& & & & P2 $<0.001$ \\
\hline
\end{tabular}

$\boldsymbol{P} \mathbf{1}=U C$ versus control, $\boldsymbol{P} 2=C D$ versus control, $\mathbf{p} 3=U C$ versus $C D$

Table 4. Sensitivity and specificity of serum miRNA $106 \&$ serum miRNA 223

\begin{tabular}{lcccc}
\hline & $\begin{array}{c}\text { AUC } \\
(\mathbf{9 5 \%} \text { CI })\end{array}$ & $\begin{array}{c}\text { Sensitivity } \\
(\mathbf{9 5 \%} \text { CI })\end{array}$ & $\begin{array}{c}\text { Specificity (95\% } \\
\text { CI) }\end{array}$ & $\begin{array}{c}\text { Accuracy (95\% } \\
\text { CI) }\end{array}$ \\
\hline miRNA 106 & $0.70(0.58-0.88)$ & $72.8(54.8-82.8)$ & $68.7(47.6-81.9)$ & $73.2(55.3-83.6)$ \\
\hline miRNA 223 & $0.65(0.59-0.87)$ & $69.0(49.9-78)$ & $62.5(47.6-72.9)$ & $69.7(58.6-79.9)$ \\
\hline
\end{tabular}

AUC: Area under the curve

Table 5. Comparison of expression levels of serum miRNA $106 \&$ serum miRNA 223 inactive and inactive IBD patients and in the control group.

\begin{tabular}{lcccc}
\hline Parameter & $\begin{array}{c}\text { Fold change of } \\
\text { serum miRNA 106 } \\
(\text { Mean } \mathbf{+} \text { SD) }\end{array}$ & P-value & $\begin{array}{c}\text { Fold change of } \\
\text { serum miRNA 223 } \\
\text { (Mean } \pm \text { SD) }\end{array}$ & P-value \\
\hline Control group(no=40) & 1 & - & 1 & - \\
Inactive UC(no=13) & $2.01 \pm 1.03$ & $\mathrm{P} 1<0.001$ & $1.59 \pm 1.26$ & $\mathrm{P} 7<0.05$ \\
Active UC(no=27) & $2.78 \pm 1.26$ & $\mathrm{P} 2<0.001$ & $2.58 \pm 1.22$ & $\mathrm{P} 8<0.001$ \\
& & $\mathrm{P} 3<0.05$ & & $\mathrm{P} 9<0.001$ \\
\hline Inactive CD(no=17) & $3.26 \pm 1.02$ & $\mathrm{P} 4<0.001$ & $2.38 \pm 1.10$ & $\mathrm{P} 10<0.001$ \\
Active $\mathbf{C D}(\mathbf{n o = 2 3})$ & $4.96 \pm 1.99$ & $\mathrm{P} 5<0.001$ & $4.02 \pm 1.18$ & $\mathrm{P} 11<0.000$ \\
& & $\mathrm{P} 6<0.001$ & & $\mathrm{P} 12<0.001$ \\
\hline
\end{tabular}

$P 1$ value to show the difference between the inactive UC and the control group as regards serum levels of miRNA106; P2 value to show the difference between the active UC and the control group as regards serum levels of miRNA106; P3 value to show the difference between the active UC and the inactive UC group as regards serum levels of miRNA106; P4 value to show the difference between the inactive CD and the control group as regards serum levels of miRNA 106; P5 value to show the difference between the active $C D$ and the control group as regards serum levels of miRNA 106; P6 value to show the difference between the inactive $C D$ and active $C D$ as regards serum levels of miRNA106; P7 value to show the difference between the inactive UC and the control group as regards serum levels of miRNA 223; P8 value to show the difference between the active UC and the control group as regards serum levels of miRNA223; P9 value to show the difference between the active UC and the inactive UC group as regards serum levels of miRNA223; P10 value to show the difference between the inactive $C D$ and the control group as regards serum levels of miRNA 223; P11 value to show the difference between the active $C D$ and the control group as regards serum levels of miRNA 223; P12 value to show the difference between the inactive $C D$ and active $C D$ as regards serum level of miRNA223. 


\section{Discussion}

Differentiation between ulcerative colitis and Crohn's disease is very serious, however, sometimes may be very hard in many cases in particular isolated colonic phenotype of Crohn's disease and ulcerative colitis $^{\mathbf{3 0 , 3 1}}$. Both ESR and CRP are the most frequently used biomarkers determining the activity of IBD, however, unfortunately they are of low specificity in these patients as they are highly expressed in many other pathological conditions ${ }^{32,33}$. Fecal calprotectin is another noninvasive commonly used marker for IBD, but, still also nonspecific and is present in some other inflammatory diseases ${ }^{12,13}$. A large number of studies showing the pathological significance of dys regulated miRNAs in many pathological disorders as cancers of the esophagus, breast, bile duct, prostate, pancreas and other immune disorders such rheumatoid arthritis and systemic lupus erythematosus ${ }^{19,34-38}$. Many studies showed variable expression patterns of miRNA in the peripheral blood in IBD patients (UC \&CD) if compared to control groups ${ }^{\mathbf{3 9 - 4 2}}$. Other studies indicated the association between expression patterns of specific miRNA and different IBD activity stages that supports their potential usefulness as biological biomarkers for the diagnosis of IBD and differrentiation of the different major types and stages of activity. In our study, we compared the expression levels of the peripheral blood of miRNA-106 and miRNA -223 in a number of IBD patients (40 ulcerative colitis and 40 Crohn's disease patients) to the levels of 40 individuals as a control group and the different expression levels in the different activity stage groups. Significantly higher expression levels of miRNA-106 \& miRNA 223 in IBD (UC \& CD) patients compared to the control group and the expression levels are higher with increased activity of the disease. Our results are in agreement with the studies of $\mathrm{Wu}$ et al. ${ }^{\mathbf{4 3 , 4 4}}$ and Zahm et al. ${ }^{45}$ on IBD patients that have revealed that peripheral blood miRNAs can distinguish between active IBD subtypes and healthy controls. Also, studies of Wu et al., and Fasseu et al. on peripheral blood and biopsies of the sigmoid colon from patients of IBD (UC and CD) have revealed that miR106 levels are significantly higher in these patients when compared to control groups ${ }^{\mathbf{4 3 4 6}}$. Wu et al. also observed that mi-RNA expression levels are increased in biopsies of patients with active $\mathrm{CD}$ and ileal CD (Crohn' sileitis) and colonic CD (Crohn's colitis) ${ }^{44}$. Paraskevi and colleagues showed that miR-106a was significantly increased in peripheral blood of active CD patients when compared to healthy controls ${ }^{47}$. Studies of Zahm and colleagues on the peripheral blood of active pediatric CD patients have indicated that miR-106a expression was significantly higher compared with healthy controls ${ }^{45}$. Our study is also in agreement with the study of Duttagupta et $\mathrm{al}^{48}$ that revealed that expression levels of miR106a in the blood are elevated in Crohn's disease and ulcerative colitis. In agreement with our study, Polytarchou et al recently recognized that miR223 was increased in the peripheral blood of UC patients compared with the healthy control group ${ }^{49}$. Another study by Wang et al., indicated increased peripheral blood miRNA in patients of ulcerative colitis and Crohn's and levels are more correlated with the factors of activity than ESR and CRP ${ }^{50}$.

\section{Conclusion}

Our present study revealed that the expression levels of miRNA 106 and miRNA 223 are higher in the peripheral blood of IBD patients and the elevation is correlated with the disease activity, so they may have an important role as a novel biomarker in the diagnosis of IBD and evaluating the disease activity.

\section{References}

1. Lawrance I, Fiocchi C, Chakravarti S. Ulcerative colitis and Crohn's disease: Distinctive gene expression profiles and novel susceptibility candidate genes. Hum Mol Genet. 2001; 10: 445-456.

2. Okahara S, Arimura Y, Yabana T, et al. Inflammatory gene signature in ulcerative colitis with cDNA macro array analysis. Aliment Pharmacol Ther. 2005; 21: 1091-1097.

3. Yu Q, Zhang S, Li L, et al. Enterohepatic helicobacter species as a potential causative factor in inflammatory bowel disease: A meta analysis. Medicine. 2015; 94: e1773.

4. Ordas I, Eckmann L, Talamini M, et al. Ulcerative colitis. Lancet. 2012; 80 (9853), doi: 10. 1016/S0140-6736(12)60150-0.

5. Abraham C, Cho J. Inflammatory bowel disease. N. Engl. J. Med. 2009; 361 (21): 2066e2078.

6. Geboes K, Colombel J, Greenstein A, et al. Indeterminate colitis: A review of the concept-what's in a name? Inflamm Bowel Dis. 2008; 14: 850-857.

7. Farmer M, Petras R, Hunt L, et al. The importance of diagnostic accuracy in colonic inflammatory bowel disease. Am J Gastroenterol. 2000; 95: 3184-3188.

8. Tremaine W. Is indeterminate colitis determinable?. Curr Gastroenterol Rep. 2012; 14: 162-165. 
9. Wang $\mathrm{H}$, Chao K, Ng S, et al. Pro-inflammatory miR-223 mediates the cross-talk between the IL23 pathway and the intestinal barrier in inflammatory bowel disease. Genome Biol. 2016; 17: 58. 10.1186/s13059-016-0901-8.

10. Annese V, Daperno M, Rutter $M$, et al. European evidence based consensus for endoscopy in inflammatory bowel disease. J Crohns Colitis. 2013; 7: 982-1018.

11. Lewis J. The utility of biomarkers in the diagnosis and therapy of inflammatory bowel disease. Gastroenterology. 2011; 140: 18171826.

12. Shastri Y, Bergis D, Povse N, et al. Prospective multicenter study evaluating fecal calprotectin in adult acute bacterial diarrhea. Am J Med. 2008; 121: 1099-1106.

13. Ertekin V, Selimoglu M, Turgut A, et al. Fecal calprotectin concentration in celiac disease. J Clin Gastroenterol. 2010; 44: 544-546.

14. Soubieres A, Poullis A. Emerging role of novel biomarkers in the diagnosis of inflammatory bowel disease. World J Gastrointest Pharmacol Ther. 2016; 7: 41-50.

15. Weber J, Baxter D, Zhang S, et al. The microRNA spectrum in 12 body fluids, Clin. Chem. 56 (11) (2010) 1733e1741.

16. Johnston D, Williams M, Thaiss C, et al. Loss of microRNA-21 influences the gut microbiota causing reduced susceptibility in a murine model of colitis. J Crohns Colitis. 2018; 12: 835-848.

17. Li M, Zhang S, Qiu Y, et al. Upregulation of miR-665 promotes apoptosis and colitis in inflammatory bowel disease by repressing the endoplasmic reticulum stress components XBP1 and ORMDL3. Cell Death Dis. 2017; 8: e2699.

18. Calin G, Ferracin M, Cimmino A, et al. A MicroRNA signature associated with prognosis and progression in chronic lymphocytic leukemia. N. Engl. J. Med. 2005; 353 (17): 1793-1801.

19. Dai Y, Huang Y, Tang M, et al. Microarray analysis of microRNA expression in peripheral blood cells of systemic lupus erythematosus patients. Lupus. 2007; 16: 939-946.

20. Lee R, Feinbaum R, Ambros V. The C. elegans hetero chronic gene lin-4 encodes small RNAs with antisense complementarity tolin-14. Cell. 1993; 75: 843-854.

21. Wu F, Zikusoka M, Trindade A, et al. MicroRNAs are differentially expressed in ulcerative colitis and alter expression of macrophage inflammatory peptide-2 alpha. Gastroenterology. 2008; 135: 1624-1635.

22. Whiteoak S, Felwick R, Sanchez-Elsner T, et al. MicroRNAs in inflammatory bowel diseases: Paradoxes and possibilities. Inflamm Bowel Dis. 2015; 21: 1160-1165.
23. Satsangi J, Silverberg $M$, Vermeire $S$, et al. The Montreal classification of inflammatory bowel disease: Controversies, consensus, and implications. Gut. 2006; 55: 749-753.

24. Sostegni R, Daperno M, Scaglione N. Review article: Crohn's disease: Monitoring disease activity. Aliment Pharm Ther. 2003; 17 (Suppl 2): 11.

25. Magro F, Gionchetti $P$, Eliakim R, et al. European evidence-based consensus on diagnosis and management of ulcerative colitis. part 1: Definitions, diagnosis, extra-intestinal manifestations, pregnancy, cancer surveillance, surgery, and ileo-anal pouch disorders. J Crohns Colitis. 2017; 11: 649-670.

26. Annese V, Daperno M, Rutter $M$, et al. European evidence based consensus for endoscopy in inflammatory bowel disease. J Crohns Colitis. 2013; 7: 982-1018.

27. Travis S, Schnell D, Krzeski P, et al. Developing an instrument to assess the endoscopic severity of ulcerative colitis: The Ulcerative Colitis Endoscopic Index of Severity (UCEIS). Gut. 2012; 61: 535-542.

28. D'Haens G, Ferrante $M$, Vermeire S, et al. Fecal calprotectin is a surrogate marker for endoscopic lesions in inflammatory bowel disease. Inflamm Bowel Dis. 2012; 18: 22182224.

29. Xie $T$, Zhang $T$, Ding $C$, et al. Ulcerative Colitis Endoscopic Index ofSeverity (UCEIS) versus Mayo Endoscopic Score (MES) in guiding the need for colectomy in patients with acute severe colitis. Gastroenterol Rep (Oxf). 2018; 6: 38-44.

30. Braveman J, Schoetz Jr, Marcello P, et al. The fate of the ileal pouch in patients developing Crohn's disease. Dis Colon Rectum. 2004; 47: 1613-1619.

31. Brown C, Maclean A, Cohen Z, et al. Crohn's disease and indeterminate colitis and the ileal pouch-anal anastomosis: Outcomes and patterns of failure. Dis Colon Rectum. 2005; 48: 15421549.

32. Pepys M, Hirschfield G. C-reactive protein: A critical update. J Clin Invest. 2003; 111: 18051812.

33. Fengming Y, Jianbing W. Biomarkers of inflammatory bowel disease. Dis Markers. 2014; 2014: 710915 .

34. Zhao B, Liu S, Wang T, et al. Screening of microRNA in patients with esophageal cancer at same tumor node metastasis stage with different prognoses. Asian Pac J Cancer Prev. 2013; 14: 139-143.

35. Wang M, Wen $\mathrm{T}$, He L, et al. A six-microRNA set as prognostic indicators for bile duct cancer. Int J Clin Exp Med. 2015; 8: 1726117270 . 
36. Fu L, Li Z, Zhu J, et al. Serum expression levels of microRNA-382-3p, -598-3p, -1246 and -184 in breast cancer patients. Oncol Lett. 2016; 12: 2-274.

37. Thorns C, Schurmann C, Gebauer N, et al. Global microRNA profiling of pancreatic neuroendocrine neoplasias. Anticancer Res. 2014; 34: 2249-2254.

38. Epis M, Giles K, Kalinowski F, et al. Regulation of expression of deoxyhypusine hydroxylase (DOHH), the enzyme that catalyzes the activation of eIF5A, by miR$331-3 p$ and miR-642-5p in prostate cancer cells. J Biol Chem. 2012; 287: 35251-35259.

39. Dalal, S, Kwon, J. The role of MicroRNA in inflammatory bowel disease. Gastroenterol. Hepatol. (N. Y.). 2010; 6 (11): 714-722.

40. Wu F, Guo N, Tian H, et al. Peripheral blood microRNAs distinguish active ulcerative colitis and Crohn's disease. Inflamm. Bowel Dis. 2011; 17(1): 241-250.

41. Pekow J, Kwon J. MicroRNAs in inflammatory bowel disease. Inflamm. Bowel Dis. 2012; 18 (1): 187-193.

42. Iborra M, Bernuzzi F, Correale $\mathrm{C}$, et al. Identification of serum and tissue micro-RNA expression profiles in different stages of inflammatory bowel disease. Clin. Exp. Immunol; 2013, 173 (2): 250-258.

43. Wu F, Guo N, Tian, H, et al. Peripheral blood microRNAs distinguish active ulcerative colitis and Crohn's disease. Inflamm. Bowel Dis. 2011; 17 (1): 241-250.
44. $\mathrm{Wu} F$, Zhang $\mathrm{S}$, Dassopoulos $\mathrm{T}$, et al. Identification of microRNAs associated with ileal and colonic Crohn's disease. Inflamm. Bowel Dis. 2010; 16 (10): 1729-1738.

45. Zahm A, Thayu M, Hand N, et al. Circulating microRNA is a biomarker of pediatric Crohn disease. J. Pediatr. Gastroenterol. Nutr., 2011; 53 (1): 26-33.

46. Fasseu M, Tréton $X$, Guichard $C$, et al. Identification of restricted subsets of mature microRNA abnormally expressed in inactive colonic mucosa of patients with inflammatory bowel disease. PLoS One. 2010; 5 (10): e13160.

47. Paraskevi A, Theodoropoulos G, Papaconstantinou I, et al. Circulating MicroRNA in inflammatory bowel disease. J. Crohn's Colitis. 2012; 6 (9): 900-904.

48. Duttagupta R, DiRienzo S, Jiang R, et al. Genome-wide maps of circulating miRNA biomarkers for ulcerative colitis. PLoS One. 2012; 7 (2): e31241.

49. Polytarchou C, Oikonomopoulos A, Mahurkar $\mathrm{S}$, et al. Assessment of circulating microRNAs for the diagnosis and disease activity evaluation in patients with ulcerative colitis by using the nano string technology. Inflamm Bowel Dis. 2015; 21: 2533-2539.

50. Wang H, Zhang S, Yu Q, et al. Circulating MicroRNA223 is a New Biomarker for Inflammatory Bowel Disease. Medicine (Baltimore). 2016; 95 (5): e2703. 